\title{
Erratum zu: Mann vor der Menge: Gursky
}

\section{Erratum zu:}

Kapitel 11 in: Ulf Jonak, Essays zur Architektur, https://doi.org/10.1007/ 978-3-658-19129-0_11

Auf Seite 51 ging versehentlich während der Produktionsphase ein Teil des Textes in der vorletzten Zeile des ersten Absatzes verloren.

Dies ist der vollständige Absatz:

Der professionelle Flaneur geht als Einzelgänger. Der Fotograf Andreas Gursky nimmt den Standpunkt des Einsamen ein gegenüber der Flut seiner Mitmenschen. Wie Caspar David Friedrichs ,Mönch am Meer'stellt er sich der großmächtigen Kulisse. Der einzelne allein vor der Menge: „Dieser Menge eine Seele zu leihen, ist das eigenste Anliegen des Flaneurs“, sagte Walter Benjamin [, Über einige Motive bei Baudelaire'] Gursky, der Flaneur, will standhalten angesichts eines Heers von nur scheinbar Seelenlosen und hält Distanz dank seiner gezückten Waffe, der Kamera. Die Masse ist für ihn die unruhige Folie, durch die hindurch er sein Jahrhundert sieht.

Die aktualisierte Version des Kapitels kann hier abgerufen werden:

https://doi.org/10.1007/978-3-658-19129-0_11

(C) Springer Fachmedien Wiesbaden GmbH 2018

E1

U. Jonak, Essays zur Architektur,

https://doi.org/10.1007/978-3-658-19129-0_33 